\title{
DESAFÍOS A LA FORMACIÓN SACERDOTAL, HOY. NATURALEZA Y MISIÓN DEL SACERDOCIO MINISTERIAL.
}

\author{
Mons. Mauro Piacenza, Arzobispo titular de Vittoriana, \\ Secretario de la Congregación del Clero
}

DOI: https://doi.org/10.52039/seminarios.v54i189-190.519

1. Fundamentos y naturaleza de la vocación sacerdotal (20); 2. El ministerio, camino de santificación (26); 
Eminencia y Excelencias Revererendísimas, Reverendísimo Rector

Queridos y venerados hermanos.

Me siento feliz de estar entre vosotros para abrir los trabajos de estas jornadas sacerdotales, organizadas a partir de la Pastores dabo vobis $(25$ de marzo de 1992).

La exhortación apostólica postsinodal del Siervo de Dios Juan Pablo II, representa, tras los decretos del Concilio Vaticano II Optatam totius y Presbiterorum ordinis, la referencia más elocuente e inmediata, bien para la formación sacerdotal hoy, bien para una lectura y una interpretación correctas de estos preciosos textos conciliares.

El trabajo de Secretario de la Congregación del Clero me llama cada día a dar un vistazo, tendencialmente universal y ciertamente apasionado, a la situación del clero en el mundo. Así, puedo constatar la dedicación, el testimonio, el generoso ministerio sacerdotal que los sacerdotes viven desde la fidelidad.

Sin embargo, al mismo tiempo, no faltan preocupaciones por la situación actual que, sobre todo en algunas regiones, reclama un profundo conocimiento para poder ser superada eficazmente.

Esta tarde, y en los próximos días, afrontareis, siguiendo la ya clásica división en cuatro partes indicada en la Pastores dabo vobis, el tema de la formación sacerdotal, analizándolo según las perspectivas humana, espiritual, intelectual y pastoral.

En esta aportación deseo, por tanto, poner el acento sobre los fundamentos de la vocación sacerdotal, sobre su naturaleza profunda, querida por el mismo Cristo, y acogida por dos mil años de tradición eclesial. y sobre el ministerio de los sacerdotes, en particular sobre el camino de santificación real que nos lleva a conseguir el servicio a Dios y a los hombres, vivido en autenticidad.

\section{Fundamentos y naturaleza de la vocación sacerdotal}

La Pdv, en el núm. 42, reconoce la raíz de la vocación sacerdotal en el diálogo entre Jesús y Pedro (cf. Jn 21); Formarse para el sacerdocio, significa habituarse a dar una respuesta personal a la pregunta fundamental de Cristo: '¿Me amas?'. La respuesta - para el futuro sacerdote- no puede ser otra que el don total de la propia vida.

Creo que tal colocación teológico-espiritual está llena de importantes con- 
secuencias que intentaremos resolver.

Pero antes querría fijar una premisa de carácter metodológico y semántico sobre el uso del término vocación. Mi impresión es que se utiliza demasiado a menudo este término para indicar no tanto una llamada específica de Cristo, sino las elecciones de vida que los hombres llevamos a cabo de forma autónoma; la consecuencia es que cualquier profesión, trabajo, condición o estado de vida es considerado una presunta vocación.

Parafraseando una afirmación teológica del Card. Cottier, según el cual si todo es gracia, nada es gracia, podemos afirmar que si todo es vocación, ¡nada es vocación!.

Presentar todo como vocación, sin las distinciones necesarias, conlleva el riesgo de una grave nivelación, de un horizontalismo artificial y de una normalización de la vocación, que resultaría ser el resultado de una mera elección humana.

Si es cierto, lícito e incluso una obligación hablar de la vocación universal a la santidad o de vocación a la vida, debemos reconocer que este lenguaje pertenece al esquema teológico-moral que tiene en el P. Haring uno de sus mayores referentes, y que interpreta la relación de salvación según el doble esquema: Dios llama - el hombre responde.

No podemos pasar por alto los méritos de tal afirmación, pero hemos de valorar también sus límites.

En efecto, si no es comprendida adecuadamente, corre el peligro de no tener en cuenta la dramática realidad del pecado original, pecando así a su vez, de un cierto optimismo e irenismo antropológicos.

Personalmente, estoy convencido de que se puede, y se debe, volver a distinguir entre vocación natural y sobrenatural, reservando sólo a esta última, en sentido estricto, el significado auténtico de vocación. En este sentido, por ejemplo, el matrimonio es, y como tal permanece, una realidad bellísima, a la que es naturalmente llamado todo hombre sanamente orientado; por tanto, propiamente no tiene sentido hablar de vocación matrimonial, si no es clarificando que se trata, más que de una vocación de una inclinación natural.

El matrimonio cristiano sacramental será después descrito con acentos vocacionales porque lo instituido por naturaleza ha sido elevado por Nuestro Señor a la dignidad de sacramento (cf. Catecismo de la Iglesia Católica, núm. 1601). Pero, ciertamente, no todos los movimientos del alma humana pueden tener origen sobrenatural: bien podemos imaginar lo que ocurriría si toda inclinación de los hombres fuese canonizada como presunta vocación divina. 
Está claro que tal impostación no soporta el impacto que significa verificarla con la realidad y, sobre todo, con el tamiz del drama universal del pecado, del que nunca es licito atribuir a Dios responsabilidad alguna.

Por tanto, cuando se habla de vocación es necesario recuperar el significado auténtico de los términos, reconociendo que ya la de ser cristiano es una auténtica vocación sobrenatural, pero reservando el término para aquellas que siempre han sido llamadas vocaciones: al sacerdocio y a la vida consagrada.

Si es cierto que no nacemos cristianos -sino en cierto sentido, culturalmente- también lo es que llegamos a serlo tras el encuentro con Cristo, que da a la vida un horizonte nuevo (Cf. Deus caritas est, núm 1). Y es también cierto e irrenunciable, que la vocación sacerdotal no es una elección humana, sino una llamada divina.

¡Es la entrada sobrenatural de Dios en la existencia humana!

Un Dios que llama a seguirlo radical, totalmente, renunciando a todo lo que es humanamente bueno y lícito para ser, para Él y para el mundo, la tierra prometida a la tribu de Leví, la cual, por el culto al Señor, no poseía tierra en este mundo. Recordemos el salmo: El Señor es mi heredad y mi copa (Salmo 16, 5).

Este intento de recuperación semántica del término vocación tiene enormes consecuencias de carácter metodológico, sobre todo en orden al discernimiento vocacional: si la vocación es un evento sobrenatural, el discernimiento ha de ser llevado a cabo con métodos sobrenaturales.

Por ejemplo, discernir la vocación usando sólo técnicas sobrenaturales, sería una violencia al objeto, que impone ex natura sui, el método del conocimiento.

La psicología es un método natural, resultando pues inadecuado para discernir la vocación sobrenatural. Las ciencias humanas pueden regsultar sumamente útiles para trabajar la parte humana que debe acoger la gracia sobrenatural de la vocación, pero no pueden volverse nunca criterio último de discernimiento vocacional.

Es necesario tener presente que el Señor da, a quienes llama, incluso la gracia de un extraordinario florecimiento humano: la humanidad, tocada por la gracia de la vocación sobrenatural al sacerdocio -y en general a la virginidad por el reino de los cielos- florece como no podría pensarse y, como certifica la experiencia en la Congregación, si abandona el camino de la vocación, se aja repentinamente.

La vocación sacerdotal es, por tanto, un evento sobrenatural de gracia, una intervención libre y soberana del Señor que Llamó a los que quiso y 
ellos le siguieron. Eligió a doce para que estuvieran con él y para enviarles (Mc 1, 13; cf Pastores dabo vobis, núm 65).

La libertad humana responde a este acontecimiento sobrenatural adhiriéndose a la divina voluntad y conformándose con ella.

Volviendo al incipit de esta contribución, a Pastores dabo vobis 42, podemos decir que como fundamento de la vocación sacerdotal está la relación de inmenso amor, apasionado, exclusivo, totalizante, entre Cristo el Señor y el llamado. Sin esta experiencia arrebatadora, que cambia y, en cierto sentido, remueve la vida, no hay auténtica vocación, no hay una verdadera comprensión del potente actuar de Dios en la vida de cada uno.

Este amor, sin duda de origen divino, ocupa realmente el corazón humano, la inteligencia, la libertad, la voluntad y la afectividad del llamado, ya que, por la profunda unidad del ser humano, todas las dimensiones del yo son como ocupadas y profundamente modeladas por la llamada del Señor.

Este amor por el Señor, único fundamento real de la vocación, se documenta en un aspecto hoy por desgracia no suficientemente subrayado, pero absolutamente central en la vida del seminarista y del sacerdote: el amor a la divina presencia de Cristo Resucitado en la Eucaristía. Creo que la adoración eucarística debería llegar a ser una práctica cotidiana y prolongada, hasta el punto de marcar la formación tanto inicial como permanente. Cuántas, cuántas cosas maduran bajo el sol eucarístico. Y si nos ponemos morenos estando al sol ¿qué proceso de crecimiento, de cristificación, no tendrá lugar estando bajo los rayos del sol eucarístico?

La vocación nace, crece, se desarrolla, se mantiene fiel y fecunda sólo en una intensa relación con Cristo.

Desde la adoración de la presencia real, la inteligencia debe entender que es Jesús de Nazaret, Señor y Ungido, la única verdad, la verdad total, el único Salvador. De no ser así ¿cómo podría inculturizarse cristianamente el futuro sacerdote? ¿De dónde puede alimentarse esa fuerza misionera que debe urgirle como un torrente?

Ciertamente, la promoción de los valores humanos y un genérico sentimiento de solidaridad no son razones suficientes para dar la vida en el martirio cotidiano de la virginidad, la obediencia, el servicio y, llegado el caso, en el martirio del testimonio hasta la efusión de sangre. ¡No se da la vida por una idea o por un valor! ¡Se da la vida por una persona! Una persona conocida, amada y que nos ama; ésta es la relación con Cristo, además de la inteligencia y de la verdadera formación intelectual. 
En la adoración de la presencia real, el corazón debe sentir la exclusividad del amor. Un amor que incendia todo en nosotros y a nuestro alrededor. La verdadera raíz del celibato está en este amor. Lejos de ser una mera norma disciplinar, como algunos quieren dar a entender, el sagrado celibato, o mejor, la virginidad por el reino de los cielos, es la traducción existencial de la Apostolica vivendi forma que, imitando al mismo Jesús, pone a Dios en el primer y único lugar, incluso en los afectos.

Desde la adoración de la presencia real se comprende incluso el sentido profundo de la disciplina eclesiástica, es decir, del ser discípulos de Cristo en la Iglesia. La tan vituperada disciplina eclesiástica no es más que saber ser discípulos.

Debemos recuperar urgentemente las raíces hechas de amor a Cristo y a las almas por Cristo.

La adoración de la presencia real es la verdadera y, en el fondo, única escuela de alegría, en Cristo hasta el sacrificio es alegría, porque por él participamos del plan de salvación de los hombres querido por Dios

Desde esta óptica, la penitencia es recuperada en su valor sobrenatural, convirtiéndose en una verdadera y propia virtud, en aquella tradición, ciertamente no banal, cargada de amor y ternura hacia el Señor, hecha de continuas atenciones con él, de aquella permanente memoria crucis que caracteriza la vida de los santos y los místicos, hasta la justa recuperación de las florecillas, es decir, aquellos actos continuos de memoria y ofrecimiento que hacen que el día quede totalmente lleno de la presencia de Cristo. Son necesarias, sin embargo, humildad, simplicidad e infancia espiritual.

Sólo desde esta óptica, incluso en la formación permanente y en la del seminarista, es posible entender en la propia carne lo que significa la pertenencia al cuerpo místico y el actuar in persona Christi, participando -incluso con los propios sufrimientos- en el misterio de la sustitución vicaria que el sacerdote está llamado a vivir en sí mismo cada día.

Un sacerdote que tenga esta conciencia de la presencia real de Cristo, será un hombre de Dios, casto, obediente, totalmente apartado de sí mismo y, por tanto, jlibre!

En la Iglesia, la obediencia es ciertamente un consejo evangélico, una virtud moral, pero es sobre todo una representación permanente del mismo Cristo obediente hasta la muerte, y una muerte de cruz (Cf. Fil 2,8), representación de aquel amor que es la redención que corre por el árbol de la cruz, que es obediencia, y esta obediencia es amor, ipuro amor!

Sólo en estas condiciones es posible educar en el verdadero sentido de 
la Iglesia, en el amor a la Santa Madre que nos ha engendrado y engendra a todos, en la fe y en el santo sacerdocio católico.

Por mucho tiempo y en demasiados lugares, se ha dejado que el mundo educase a los seminaristas, dejados, abandonados a la ósmosis con el clima difuso de una sociedad relativista, hedonista, narcisista y, en definitiva janticatólica!

De tal modo se ha permitido que el mundo condicionase el pensamiento de los seminaristas, su modo de hablar, el criticar y juzgar a la Madre, la Iglesia, el ceder a categorías histórico-políticas, impuestas por la hermenéutica de la discontinuidad, dentro del único sujeto eclesial Incluso el vestir, el cantar, un cierto irresponsable sexualizar, con un uso inmaduro y superficial de la gestualidad, todo ello aspectos copiados del mundo. Bien sabemos que el espíritu del mundo y el de Dios son opuestos. Así como sabemos que el lugar teológico no es el mundo, sino la Iglesia, presencia de Cristo en el mundo,

¿En qué se diferencian algunos seminaristas de sus secularizados coetáneos?

Se ha creado no una herejía, lo que habría hecho reaccionar rápidamente a la Iglesia, sino un clima general, una niebla que lo rodea todo, haciendo imposible ver y distinguir con claridad entre el bien y el mal, verdadero y falso, vicio y virtud. Podremos encontrar una analogía para entenderlo en aquello que, primero a nivel filosófico y después divulgativo, ha ocurrido con el término moderno: una realidad, en lenguaje común, es buena si es moderna. No importa que sea verdadera o falsa, que promueva verdaderamente al hombre o lo dañe; no nos preguntamos nada sobre esto. Es suficiente que sea moderna para que resulte simpática y encuentre acogida en las mentes, los corazones y las costumbres.

Lo mismo ocurre en algunos ambientes eclesiales: basta utilizar locuciones que hoy son ya famosas: después del Concilio o según el Concilio y nadie osa ni siquiera comprobar si aquella noble asamblea de Padres haya hecho nunca determinadas afirmaciones.

Baste pensar en algunas palabras clave con las que son humillados, y se pierden óptimas vocaciones: es muy rígido... demasiado ligado a las formas... no está abierto a la diversidad... está demasiado convencido... no tiene dudas... no ha elaborado críticamente la fe... rompe la comunión etc.

Es necesario romper los equívocos y llamar al pan, pan y al vino, vino, porque si no hay claridad en los síntomas, no se puede hacer un diagnóstico y no se podrá construir un modo auténticamente católico y moderno de formar al futuro clero del mundo. 


\section{El ministerio, camino de santificación}

A la luz de lo dicho, se comprende como hay que presentar, acoger y vivir el ministerio. En muchas ocasiones, pero sobre todo en la Deus caritas est, el Santo Padre Benedicto XVI ha proclamado la urgencia de superar toda reducción funcional y activista del trabajo eclesial y, especialmente, del ministerio sacerdotal.

Lo específico de la vocación sacerdotal, esencial e imprescindible para la vida y la identidad de la Iglesia -y esto se dice frente a no pocos atentados contra la identidad y el consiguiente ministerio pastoral de los presbíteros- postula como lógica consecuencia lo específico del camino de santidad que todo sacerdote está llamado a recorrer a través del ejercicio de su ministerio.

Redescubramos en este sentido la centralidad de la Eucaristía: fuente y culmen de todo el ministerio sacerdotal, y, a la vez, centro propulsor de la vida moral y de la santificación del clero

Celebrémosla con la sorpresa agradecida de un niño, con la consciencia profunda de un místico, con la cuidadosa preparación de un enamorado, en el silencio orante de quien es consciente de encontrarse al servicio de Dios, deseando desaparecer, disminuir para que él crezca (Cf. Jn 3, 30).

Que el ministerio no sea distinto de la vida del sacerdote quien, en cada actividad, debe mantener siempre un estilo sacerdotal, como si siempre estuviera sobre las gradas del altar: en el trato humano, en el lenguaje, en el traje propio -que expresa un actuar y un ser específicos-, en el actuar constantemente como lo hace el Buen Pastor que se ofrece por las ovejas, que no es nunca un mero administrador o, lo que es peor, un mercenario capaz de apartar a las ovejas del redil de la santa Iglesia.

Tal trato humano no nace de un esfuerzo improvisado sino de la consciencia, debidamente educada, de ser por pura gracia y misericordia divina, un alter Christus que peregrina por los caminos del mundo.

Esto es ser sacerdote; ésta es la verdadera pastoral.

No ceder a las modas ni a los gustos de los tiempos ni de los hombres, no secundarlos en el pecado personal y social, sino curar a las ovejas, con especial atención a las alejadas y enfermas, partiendo del ardiente deseo de que todos conozcan a Cristo, verdadero y único Salvador de la historia y del hombre, de que los confines visibles de la Iglesia se dilaten hasta los confines del mundo.

Todos los hombres son llamados a formar parte del rebaño de Cristo. El sacerdote llega a ser santo actuando en esa dirección, viviendo, sufrien- 
do, ofreciéndose para que todos los que le han sido confiados, y aun los que encuentra, puedan lograr una verdadera experiencia de Cristo a través de su ministerio y de su trato humano.

El sacerdote no puede refugiarse en la soledad o el aislamiento, no puede pensar que la edad canónica del retiro coincida con dejar de trabajar por el bien de las almas.

El sacerdocio sacramental modifica ontológicamente la identidad de quien lo ha recibido. Se es sacerdote para siempre, incluso más allá de la muerte.

Ningún ministerio, ni el más teológicamente cualificado, admitiendo que se trate de sana teología, podrá nunca sustituir al sacerdote.

Eduquemos en esta consciencia. Renovemos nuestra pertenencia a Cristo y el amor por esta Eucaristía que, por pura gracia, podemos celebrar.

Amemos el confesonario como lugar, como servicio, como identificación con Cristo misericordioso, dador del amor trinitario.

Que la santísima virgen María, madre de los sacerdotes, proteja nuestro camino de santificación, refuerce nuestra consciencia de ser hijos suyos y dé a la Iglesia una nueva estación de florecimiento vocacional y de sacerdotes santos.

Creo que, en este sentido, la tormenta ya escampa. Gracias. 